\title{
PENGARUH KOMPETENSI SDM, PELATIHAN DAN PROMOSI JABATAN TERHADAP KINERJA PEGAWAI DI DINAS PENANAMAN MODAL DAN PELAYANAN TERPADU SATU PINTU KOTA BATAM
}

\author{
Rahman Hasibun ${ }^{1)}$, Mira Yona ${ }^{2)}$, Kasmawati ${ }^{3)}$ \\ Program Studi Manajemen Universitas Riau Kepulauan Batam \\ rahmanhasibuan@gmail.com ${ }^{1)}$ \\ Program Studi Manajemen Universitas Riau Kepulauan Batam \\ mirayona@yahoo.co.id2 ${ }^{2)}$ \\ Program Studi Manajemen Universitas Riau Kepulauan Batam \\ Kasma1693@gmail.com ${ }^{3)}$
}

\begin{abstract}
ABSTRAK
Tujuan penelitian ini adalah untuk mengetahui pengaruh Kompetensi, Pelatihan dan Promosi Jabatan terhadap kinerja pegawai di Dinas Penanaman Modal dan Pelayanan Terpadu Satu Pintu Kota Batam.Penelitian ini menggunakan metode kuantitatif dengan penyebaran kuisioner kepada 114 karyawan yang bekerja di Dinas Penanaman Modal dan Pelayanan Terpadu Satu Pintu Kota Batam Sampel diambil dengan teknik systematic random sampling dan menggunakan perhitugan Slovin dengan tingkat kesalahan sebesar $10 \%$. Metode analisis data yang digunakan adalah analisis kuantitatif, yaitu uji reliabilitas dan uji validitas, uji asumsi klasik, uji T dan uji F, koefisisen determinasi serta analisis regresi linear berganda.Dari hasil regresi berganda, menunjukan bahwa secara parsial maupun simultan (bersama-sama) Kompetensi SDM, Pelatihan dan Promosi Jabatan memiliki pengaruh yang signifikan terhadap Kinerja Pegawai
\end{abstract}

\section{Kata kunci : Kompetensi SDM, Pelatihan dan Promosi Jabatan}

\section{ABSTRACT}

The purpose of this study was to study the Competency, Training and Job Promotion research on employee performance at the Batam City Investment and One Stop Integrated Services Office. This research uses a quantitative method by distributing questionnaires to 114 companies working in the Investment and One Stop Integrated Services Office Batam City Samples were taken by systematic random sampling technique and using Slovin calculations with an error rate of 10\%. Data analysis method used is quantitative analysis, namely the reliability and validity test, the classic assumption test, the $T$ test and the $F$ test, the coefficient of determination and multiple linear regression analysis. Multiple regression results, displayed partially and simultaneously (together) HR Competency, Training and Promotion have a significant effect on Employee

\section{Performance Keywords: HR Competency, Training and Job Promotion}




\section{PENDAHULUAN}

Sumber daya manusia merupakan salah satu asset paling berharga yang dimiliki oleh suatu organisasi, karena manusialah yang merupakan satu-satunya sumber daya yang dapat menggerakkan sumber daya lainnya.Dengan demikian, unsur sumber daya manusia merupakan faktor kunci yang harus dipertahankan suatu organisasi sejalan dengan tuntutan yang senantiasa dihadapi organisasi untuk menjawab setiap tantangan yang ada.Oleh karena itu, upaya untuk mempertahankan sumber daya manusia yang berkualitas merupakan langkah utamaorganisasi.

Menurut Marshal (2013), kompetensi merupakan hal yang paling sulit ditiru, karena karakteristiknya yang memang berbeda dan spesifik bagi masing-masing individu. Diera globalisasi berbasis pengetahuan sekarang ini, kompetensi merupakan asset utama dalam organisasi, sebagai sumber untuk membangun dan meraih keunggulan bersaing secara berkelanjutan. Oleh sebab kompetensi dibutuhkan untuk dapat menyelesaikan masalah-masalah pegawai seperti kurang cepat dalam memecahkan masalah, kurang berinovasi dalam bekerja, belum memahami standar perusahaan dengan baik, informasi dari lapangan belum direspon dengan baik oleh pegawai, dengan adanya penerapan kompetensi di perusahaan, kinerja pegawai akan semakinbaik.

Kompetensi sumber daya manusia (SDM) dapat memberikan karakteristik aspek Skill, Knowledge, Self-concept, Self Image, Trait dan Motive.tertentu pada prestasi kerja individu yang akhirnya akan nampak pula pada peningkatan hasil kerja.

Kompetensi yang memadai akan memacu semangat serta, kreativitas dalam bekerja sehingga dapat menunjukkan kinerja yang baik dan pada akhirnya dapat meningkatkan produktivitas dan kinerja pegawai.

Ketidakpuasan kerja karyawan akan menimbulkan keinginan untuk keluar dari organisasi, tetapi kesempatan kerja juga akan mempengaruhi tingkat kepuasan atau keinginan untuk keluar. Penilaian individu terhadap posisi sekarang dan merasa tidak puas dapat memicu seseorang untuk mencari pekerjaan lain.

Faktor lain yang mempengaruhi kinerja Pegawai adalah Pelatihan pegawai merupakan kegiatan pengembangan sumber daya manusia untuk meningkatkan pengetahuan, kemampuan dan ketrampilan serta meningkatkan kinerja pegawai. Pendidikan berupaya mengembangkan kemampuan intelektual dan

kepribadian pegawai, oleh karena itu setiap organisasi yang ingin berkembang harus benar-benar memperhartikan pendidikan dan pelatihan

$$
\text { pegawai }
$$

sehinggaberpengaruh terhadap kinerja karyawan.

lebih ditekankan pada unsur kesadaran individu untuk mengikuti peraturan- peraturan yang berlaku dalam organisasi. Namun berbeda dengan penelitian yang dilakukan oleh Utari (2015) yang menunjukkan bahwa variabel pelatihan berpengaruh terhadap variabel kinerja pegawai. Dalam hal ini Pelatihan penting bagi organisasi sebab akan ditaati oleh sebagian besar pegawai dan diharapkan pekerjaan akan dilakukansecara efektif. Oleh karena itu, perlu upaya pemimpin untuk membuat karyawannya bekerja secara disiplin dan pemimpin tersebut juga harusdapat menunjukkan cara yang paling baik dan membantu karyawan bertindak disiplin dalam menyelesaikan tugas / pekerjaansehari-harinya.Selain ompetensi SDM, Pelatihan ada faktor kinerja pegawai yaitu promosi jabatan Promosi jabatan adalah kebijakan yang ada 
diruang lingkup organisasi Dinas Penanaman Modal dan Pelayanan Terpadu Satu Pintu Kota Batam untuk mensejahterakan karyawan, sistem pelayanan promosi jabatan yaitu dengan melihat keloyalitasan dan prestasi kerjanya memungkinkan karyawan untuk mempunyai kesempatan dipromosikan jabatannya, sehingga memacu gairah kinerja karyawan untuk menunjukan yang terbaik Hasibuan dalam winda yulyarta simanjuntak(2015).

Fenomena yang terjadi belakangan ini di Dinas penanaman modal dan pelayanan terpadu satu pintu yaitu Kompetensi sdm dimana tingkat kemampuan seorang pegawai yang belum cukup dimiliki maka akan di lakukan pelatihan dengan tujuan untuk meningkatkan kemampuan karyawan di berbagai bidang. Akan tetapi fakta yang terjadi bahkan tidak sesuai harapan yang mana dengan di kompetensi sdm membuat karyawan tidak menjalaninya karena merasa terbebani dengan pekerjaan yang baru yang tidak dikuasainya, sehingga produktivitas kerja menjadiberkurang.

\section{TUJUAN PENELITIAN}

Tujuan Penelitian ini adalah sebagai berikut:

1. Untuk menegetahui apakah kompetensi SDM berpengaruh secara langsung dan signifikan terhadap kinerja Pegawai di Dinas Penanaman Modal dan Pelayanan Terpadu Satu Pintu Kota Batam.

2. Untuk mengetahui apakah Pelatihan berpengaruh secara langsung dan signifikan terhadap kinerja Pegawai Di DinasPenanaman Modal dan Pelayanan Terpadu Satu Pintu Kota Batam.

3. Untuk mengetahui apakah promosi jabatan berpengaruh secara langsung dan signifikan terhadap kinerja
Pegawai Di DinasPenanaman Modal dan Pelayanan Terpadu Satu Pintu KotaBatam.

4. Untuk mengetahui apakah kompetensi SDM, Pelatihan danpromosi jabatan berpengaruh secara bersama-sama dan signifikan kinerja Pegawai Di Dinas Penanaman Modal dan Pelayanan Terpadu Satu Pintu KotaBatam.

mengerjakan tugas dan kewajiban jabatan (job description) secara aktual di dalam tempat kerja di berbagai jabatan (variety of jobs) dengan memindah mindahkan pegawai dari suatu jabatan kepada jabatan lain (move the trainee from job to job).

Adapun indikator Kompetensi SDM yang dikembangkan oleh Boulter, Dalziel dan Hill ( 2006)yaitu:

1. Kemampuan;

2. Pengetahuan;

3. motivasi

4. Konsepdiri

\section{Kompetensi SDM}

Kompetensi kinerja dapat diartikan sebagai perilaku-perilaku yang ditunjukkan mereka yang memiliki kinerja yang sempurna, lebih konsisten dan efektif, dibandingkan dengan mereka yang memiliki kinerja rata-rata. Dengan mengevaluasi kompetensi-kompetensi yang dimiliki seseorang, kita akan dapat memprediksikan kinerja orang tersebut, Ratnasari, Sutjahjo, dan Adam (2019).Kompetensi dapat digunakan sebagai kriteria utama untuk menentukan kerja seseorang. Misalnya, untuk fungsi profesional, manajerial atau senior manajer.Kompetensi adalah karakteristik dasar dari seseorang yang memungkinkan mereka mengeluarkan kinerja superior dalam pekerjaannya (Boulter, Dalziel dan Hill :2006).

\section{Pelatihan}

M.Yani (2012), Pelatihan dalah 
sarana meningkatkan pengetahuan dan keterampilan teknis. Sebuah perusahaan sangat membutuhkan para sumber daya manusia yang menjadi penggerak dari berbagai macam pekerjaan yang akan dikerjakan oleh karyawan. Karyawan mempunyai tingkat pekerjaan yang berbeda-beda dalam melaksanakan pekerjaan mereka namun terkadang mereka tidak tahu apa yang harus dikerjakan terkait dengan pekerjaan mereka maka dari itu sangat diperlukana adanya pelatihan bagi sumber daya manusia agar para karyawan bias paham dan mengerti atas pekerjaan mereka sehingga apa yang menjadi tujuan perusahaan dapat cepat terlaksana dan mencapai target yangdiharapkan.

\section{Promosi Jabatan}

MenurutHasibuan (2006:108) adalah promosi jabatan merupakan perpindahan yang memperbesar authority dan responbility karyawan ke jabatan yang lebih tinggi di dalam suatu organisasi sehingga hak, status, dan penghasilan mereka akan semakin besar.Hal Ini berarti seseorang memperoleh promo jabatan akan memliki wewenang dan tanggung jawab yang lebih besar karena memperoleh jabatan yang lebih tinggi. Selain itu efek yang ditimbulkan adalah hak,status,dan penghasilan yang berup aupah/gaji dan tunjangan lainnya, akan bertambah dibandingkan dengan ja batan yang diperoleh sebelumnya. berkualitas lebih baik dengan usaha yang sama.
Volume 6 No. 2 Tahun 2019

P-ISSN 2252-5262

E-ISSN 2614-499

\section{Kinerja Karyawan}

Kinerja karyawan adalah hasil kerja yang dihasilkan karyawan, bisa dalam kuantitas maupun kualitas, (Setiawati, Ratnasari, dan Hakim, 2019).

Menurut Ratnasari, Sutjahjo, dan Adam (2019), kinerja karyawan adalah hasil kerja karyawan berupa kuantitas maupun kualitas.

\section{KERANGKA PEMIKIRAN}

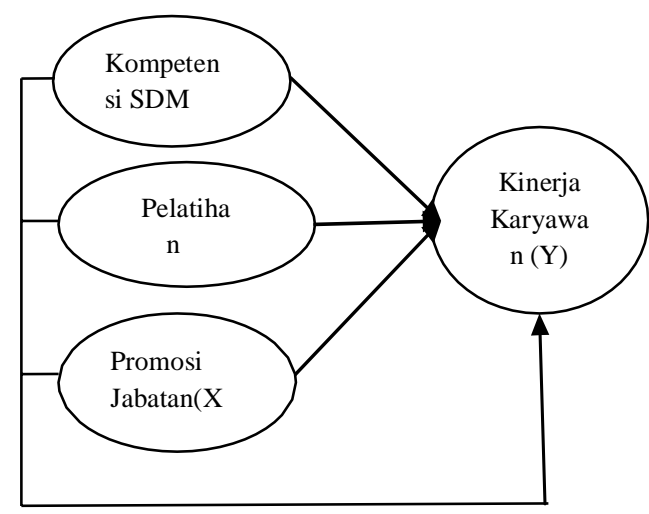

\section{METODE PENELITIAN}

\section{Teknik Pengambilan Sampel}

Menurut Sugiyono

mendefinisikan populasi merupakan totalitas dari semua objek atau individu yang memiliki karakteristik tertentu, jelas, lengkap yang akan diteliti. Objek atau nilai yang akan diteliti dalam populasi disebut unit analisis atau elemen populasi. Adapun populasi dalam penelitian ini adalah seluruh karyawan Dinas penanaman Modal dan pelayanan terpadu satu pintu kota Batam yang berjumlah 114 orang. 


\section{HIPOTESIS PENELITIAN}

H1 : Diduga Kompetensi SDM berpengaruh secara langsung dan signifikan terhadap kinerja Pegawai Di Dinas Penanaman Modal dan Pelayanan Terpadu Satu Pintu Kota Batam

$\mathrm{H} 2$ : Diduga Pelatihan berpengaruh secara langsung dan signifikan terhadap kinerja Pegawai Di Dinas Penanaman Modal dan Pelayanan Terpadu Satu Pintu Kota Batam

H3 :Di duga Promosi jabatan berpengaruh secara langsung dan signifikan terhadap kinerja Pegawai Di Dinas Penanaman Modal dan Pelayanan Terpadu Satu Pintu KotaBatam.

H4 : Di duga Kompetensi SDM, Pelatihan dan promosi jabatan berpengaruh secara bersamasama dan signifikan kinerja Pegawai Di Dinas Penanaman Modal dan Pelayanan Terpadu Satu Pintu KotaBatam.

Penarikan sampel dengan teknik systematic random sampling dan digunakan rumus slovin unt uk menentukan jumlah sampelnya. Jadi, jumlah sampel yang akan diambil dalam penelitian ini adalah $5 \quad 3$ karyawan.

Data yang digunakan dalam penelitian ini meliputi:

Data Primer, Data primer merupakan data yang diperoleh secara langsung dari umber asli (tanpa melalui perantara) Data primer yang ada dalam penelitian ini merupakan data kuesioner yang diperoleh langsung dari pengisian kuesioner oleh Pegawai Dinas penanaman modal dan pelayanan terpadu satu pintu kota batam.

Data Sekunder, Data sekunder adalah data penelitian yang diperoleh secara tidak langsung melalui media perantara
Volume 6 No. 2 Tahun 2019

P-ISSN 2252-5262

E-ISSN 2614-499

(diperolehdandicatatolehpihak lain).

Data

Sekunder dalam penelitian ini adalah data

Tentang perusahaan meliputi:

Gambaran umum perusahaan, struktur organisasi, dan informasi lainnya.

\section{TeknikPengumpulan Data}

Dalam penelitian ini data yang akan dikumpulkan berupa data primer dan data sekunder, maka penelitian menggunakan alat pengumpulan data berupa:

Kuesioner merupakan teknik pengumpulan data yang dilakukan dengan cara memberikan seperangkat pertanyaan yang berstruktur atau pernyataan secara tertulis kepada responden yang berhubungan dengan penelitian, guna mendapatkan data untuk memecahkan masalah yang diteliti.

Observasi merupakan metode pengumpulan data yang dilakukan dengan mendatangi objek penelitian secara langsung, yaitu Dinas penanaman modal dan pelayanan terpadu satu pintu kota batam Metode Dokumentasi atau Studi Pustaka Metode Dokumentasi atau Studi Pustaka adalah suatu cara yang digunakan untuk mencari data mengenai hal-hal variable berupacatatan, transkip, buku, urat, majalah, agenda dan sebagainya. Metode ini merupakan metode bantu yang digunakan untuk memperoleh data-data menyangkut informasi. Metode yang digunakan merupakan meto de pengumpulan data mengenai suatu hal yang pernah terjadi dan didokumentasi kan. Metode Wawancara atau Interview Wawancara atau interview adalah serangkaian wawancara yang dimaksudkan untuk melengkapi $\mathrm{k}$ uesioner atau jawaban yang kurang terarah, sehingga dari wawancara ini diharapkan dapat diperoleh keterangan lebih lanjut dari pihak yang 
bersangkutan.

\section{HASIL PENELITIAN}

\section{Uji Validitas}

Hasil uji validitas menunjukkan bahwa semua butir pernyataan mempunyai nilai $\mathrm{r}$ hitung $>\mathrm{r}$ tabel, dengan taraf signifikan $\alpha=0,05$ dan nilai $r$ tabel nya sebesar 0.273 dapat disimpulkan bahwa semua pernyataan pada variabel $\mathrm{X} 1, \mathrm{X} 2$, dan $\mathrm{X} 3$ dan $\mathrm{Y}$ dinyatakan validita

\section{Uji Reliabilitas}

\begin{tabular}{|l|l|l|l|l|}
\hline Variabel & $\begin{array}{l}\text { Jml } \\
\text { butir }\end{array}$ & $\begin{array}{l}\text { cronbach } \\
R \text { alpha }\end{array}$ & $\begin{array}{l}\text { Batas } \\
\text { penerimaan }\end{array}$ & Keterangan \\
\hline $\begin{array}{l}\text { Kompetensi } \\
\left(\mathrm{X}_{1}\right)\end{array}$ & 10 & 0,904 & $>0.6$ & Reliabel \\
\hline $\begin{array}{l}\text { Pelatihan } \\
\left(\mathrm{X}_{2}\right)\end{array}$ & 10 & 0.928 & $>0.6$ & Reliabel \\
\hline $\begin{array}{l}\text { Promosi } \\
\text { Jabatan } \\
\left(\mathrm{X}_{3}\right)\end{array}$ & 10 & 0.841 & $>0.6$ & Reliabel \\
\hline
\end{tabular}

Dari tabel diatas dapat dilihat bahwa $\mathrm{R}$ Alpha dari masing - masing variabel X1, X2, X3 lebih besar dari 0,0.273 Dengan demikian dapat disimpulkan bahwa data yang diuji tersebut dinyatakan reliabel.

\section{Uji Normalitas}

One-Sample Kolmogorov-Smirnov Test

\begin{tabular}{|ll|r|}
\hline & & $\begin{array}{r}\text { Unstandardiz } \\
\text { ed Residual }\end{array}$ \\
\hline $\mathrm{N}$ & Mean & 53 \\
Normal Parameters ${ }^{\mathrm{a}, \mathrm{b}}$ & Std. &, 10000000 \\
& Deviation &, 089 \\
Most Extreme & Absolute &, 077 \\
Differences & Positive &,- 089 \\
& Negative &, 630 \\
Kolmogorov-SmirnovZ & &, 823 \\
Asymp. Sig. (2-tailed) & & \\
a. Test distribution isNormal. & \\
b. Calculated fromdata. &
\end{tabular}

Berdasarkan hasil uji Kolmogorov-smirnov pada tabel 4.16 diketahui nilai Asymp. Sig. (2-tailed)
Volume 6 No. 2 Tahun 2019

P-ISSN 2252-5262

E-ISSN 2614-499

sebesar 0,823>0,05 (alpha) sehingga dapat disimpulkan bahwa data

\begin{tabular}{|c|c|c|c|c|}
\hline VARIABEL & Item & $r$ hitung & $\begin{array}{c}\mathbf{r} \\
\text { table }\end{array}$ & Hasil \\
\hline \multirow{5}{*}{$\begin{array}{c}\text { KOMPETENSI } \\
\text { SDM }\end{array}$} & X1.1 & $\begin{array}{c}\mathbf{0 , 8 6 0} \\
\text { (positif) }\end{array}$ & 0,273 & Valid \\
\hline & X1.2 & $\begin{array}{c}\mathbf{0 , 7 3 9} \\
\text { (positif) } \\
\end{array}$ & 0,273 & Valid \\
\hline & X1.3 & $\begin{array}{c}\mathbf{0 , 8 1 0} \\
\text { (positif) }\end{array}$ & 0,273 & Valid \\
\hline & X1.4 & $\begin{array}{c}\mathbf{0 , 5 5 3} \\
\text { (positif) }\end{array}$ & 0,273 & Valid \\
\hline & X1.5 & $\begin{array}{c}\mathbf{0 , 5 6 2} \\
\text { (positif) }\end{array}$ & $\mathbf{0 , 2 7 3}$ & Valid \\
\hline \multirow{5}{*}{ PELATIHAN } & X2.1 & $\begin{array}{c}0,795 \\
\text { (positif) }\end{array}$ & 0,273 & Valid \\
\hline & X2.2 & $\begin{array}{c}\mathbf{0 , 8 5 2} \\
\text { (positif) }\end{array}$ & 0,273 & Valid \\
\hline & X2.3 & $\begin{array}{c}0,737 \\
\text { (positif) } \\
\end{array}$ & 0,273 & Valid \\
\hline & X2.4 & 0,839(positif) & 0,273 & Valid \\
\hline & X2.5 & $\begin{array}{c}\mathbf{0 , 8 8 1} \\
\text { (positif) }\end{array}$ & 0,273 & Valid \\
\hline \multirow{5}{*}{$\begin{array}{l}\text { PROMOSI } \\
\text { JABATAN }\end{array}$} & X3.1 & $\begin{array}{c}\mathbf{0 , 6 6 8} \\
\text { (positif) } \\
\end{array}$ & 0,273 & Valid \\
\hline & X3.2 & $\begin{array}{c}0,667 \\
\text { (positif) } \\
\end{array}$ & 0,273 & Valid \\
\hline & X3.3 & $\begin{array}{c}0,447 \\
\text { (positif) }\end{array}$ & 0,273 & Valid \\
\hline & X3.4 & $\begin{array}{c}\mathbf{0 , 6 0 1} \\
\text { (positif) }\end{array}$ & $\mathbf{0 , 2 7 3}$ & Valid \\
\hline & X3.5 & $\begin{array}{c}\mathbf{0 , 7 9 0} \\
\text { (positif) }\end{array}$ & 0,273 & Valid \\
\hline \multirow{5}{*}{$\begin{array}{l}\text { KINERJA } \\
\text { PEGAWAI }\end{array}$} & Y.1 & $\begin{array}{c}\mathbf{0 , 8 1 6} \\
\text { (positif) } \\
\end{array}$ & $\mathbf{0 , 2 7 3}$ & Valid \\
\hline & Y.2 & $\begin{array}{c}\mathbf{0 , 7 7 7} \\
\text { (positif) }\end{array}$ & 0,273 & Valid \\
\hline & Y.3 & $\begin{array}{c}0,709 \\
\text { (positif) } \\
\end{array}$ & 0,273 & Valid \\
\hline & Y.4 & $\begin{array}{c}0,675 \\
\text { (positif) } \\
\end{array}$ & 0,273 & Valid \\
\hline & Y.5 & $\begin{array}{c}\mathbf{0 , 8 7 9} \\
\text { (positif) }\end{array}$ & 0,273 & Valid \\
\hline
\end{tabular}


mempunyai sebaran yang normal

\section{Gambar}

memperlihatk

an ketentuan bahwa titik-titik data menyebar disekitar garis diagonal dan mengikuti arah garis diagonal maka dapat dikatakan data memenuhi asumsi normalitas.

\section{Uji Multikolonieritas}

\begin{tabular}{l} 
Coefficie \\
nts $^{\mathbf{a}}$ \\
\begin{tabular}{|ll|r|c|}
\hline \multirow{2}{*}{ Model } & \multicolumn{2}{c|}{ Collinearity Statistics } \\
\cline { 3 - 4 } & & Tolerance & \multicolumn{1}{c|}{ VIF } \\
\hline 1 & Kompetensi &, 201 & 4,987 \\
& pelatihan &, 128 & 7,823 \\
& Promosi &, 147 & 6,797 \\
\hline
\end{tabular} \\
\hline
\end{tabular}

a. Dependent Variable: Kinerja

Tabel menunjukkan bahwa nilai VIF untuk variabel $\mathrm{X} 1, \mathrm{X} 2$ dan X3 masing-masing sebesar 4,987;
Volume 6 No. 2 Tahun 2019

P-ISSN 2252-5262

E-ISSN 2614-499

7,$823 ; \quad 6,797$ sehingga dapat

Normal P-P Plot of Regression Standardized Residual Dependent Variable: RATA2_PRODUKTIVITAS_KERJA

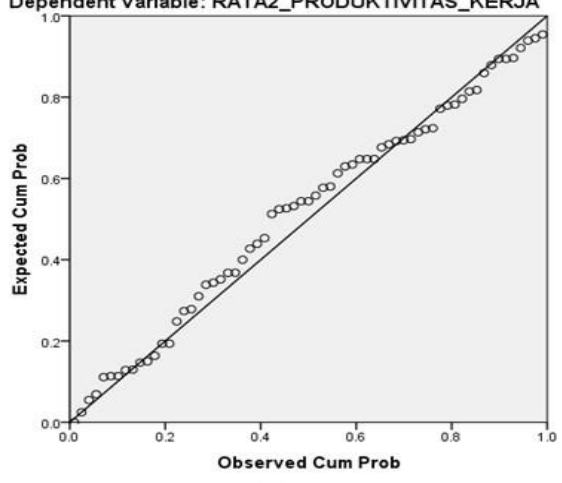

Sumber: Hasil pengollahan data SPSS V. 23

disimpulkan bahwa dalam model regresi tidak terdapat gejala multikolinearitas antar variabel bebas karena nilai VIF nya lebih kecil dari 10 yang berarti bahwa semua variabel tersebut dapat digunakan sebagai variabel yang saling independen

\section{Uji Heteroskedastisitas}

\begin{tabular}{|c|c|c|c|l|l}
\multirow{2}{*}{ Model } & \multicolumn{2}{|c|}{$\begin{array}{c}\text { Unstandardized } \\
\text { Coefficients }\end{array}$} & $\begin{array}{c}\text { Standardized } \\
\text { Coefficients }\end{array}$ & \multirow{2}{*}{ S Sig. } \\
\cline { 2 - 4 } & $\mathrm{B}$ & Std. & Beta & & \\
\hline
\end{tabular}




\begin{tabular}{|c|c|c|c|c|c|c|}
\hline & & & Error & & & \\
\hline \multirow{4}{*}{1} & (Constant) & $\begin{array}{c}5,40 \mathrm{E}- \\
15\end{array}$ & 2,043 & & 0 & 1 \\
\hline & TotalX1 & 0 & 0,092 & 0 & 0 & 1 \\
\hline & TotalX2 & 0 & 0,117 & 0 & 0 & 1 \\
\hline & TotalX3 & 0 & 0,126 & 0 & 0 & 1 \\
\hline
\end{tabular}

Hasil pengujian Park Gleyser melihat nilai probabilitas dengan signifikansi > nilai alpha $(0,05)$ maka model tidak mengalami heteroskedastisitas (Wibowo, 2012). Berdasarkan tabel 4.20 diketahui bahwa nilai probabilitas atau signifikansi dari masing-masing variabel sebesar 1,000 maka dapat disimpulkan bahwa dalam model regresi tidak terdapat gejala heteroskedastisitas.

\section{Uji T (Parsial)}

\begin{tabular}{|c|c|c|c|c|c|c|}
\hline \multirow{2}{*}{\multicolumn{2}{|c|}{ Model }} & \multicolumn{2}{|c|}{$\begin{array}{c}\text { Unstandardized } \\
\text { Coefficients }\end{array}$} & \multirow{2}{*}{$\begin{array}{c}\begin{array}{c}\text { Standardized } \\
\text { Coefficients }\end{array} \\
\text { Beta }\end{array}$} & \multirow{2}{*}{$T$} & \multirow{2}{*}{ Sig. } \\
\hline & & B & $\begin{array}{l}\text { Std. } \\
\text { Error }\end{array}$ & & & \\
\hline \multirow{4}{*}{1} & (Constant) & 0,838 & 2,043 & & j & 0,684 \\
\hline & TotalX1 & 0,293 & 0,092 & 0,3 & 3 & 0,003 \\
\hline & TotalX2 & 0,469 & 0,117 & 0,47 & 4 & 0 \\
\hline & TotalX3 & 0,258 & 0,126 & 0,22 & 2 & 0,046 \\
\hline
\end{tabular}

Tabel menunjukan bahwa variabel kompetens (X1) nilai t hitung $3,194>\mathrm{t}$ tabel 2,009 dan nilai signifikan $0,003<0,05$ sehigga keputusan yang diambil adalah $\mathrm{H}_{\mathrm{o}}$ ditolak dan $\mathrm{H}_{\mathrm{a}}$ diterima. Hal ini berarti bahwa kompetnesi berpengaruh secara positif dan signifikan terhadap Kinerja pegawai.

Variabel pelatihan (X2) menunjukkan nilai t hitung 4,020 > t tabel 2,009 dan nilai signifikan 0,000 < 0,05 sehingga keputusan yang diambil adalah $\mathrm{H}_{\mathrm{o}}$ ditolak dan $\mathrm{H}_{\mathrm{a}}$ diterima. Hal ini berarti bahwa pelatihanberpengaruh secara positif dan signifikan terhadap Kinerja pegawai.
Variabel

Promosi

Jabatan(X3) nilai $\mathrm{t}$ hitung 2,051 > t tabel 2,009 dan nilai signifikan 0,046 < 0,05 sehingga keputusan yang diambil adalah $\mathrm{H}_{\mathrm{o}}$ ditolak dan $\mathrm{H}_{\mathrm{a}}$

Hasil dari tabel menunjukkan bahwa variabel rotasi jabatan (X1) nilai t hitung 4,187 > t tabel 1,999 dan nilai signifikan $0,000<0,05 \quad$ sehingga keputusan yang diambil adalah $\mathrm{H}_{\mathrm{o}}$ ditolak dan $\mathrm{H}_{\mathrm{a}}$ diterima. Hal ini berarti bahwa kompetensi jabatan (X1) berpengaruh secar signifikan terhadap kinerja karawan

\section{Uji F (Simultan)}

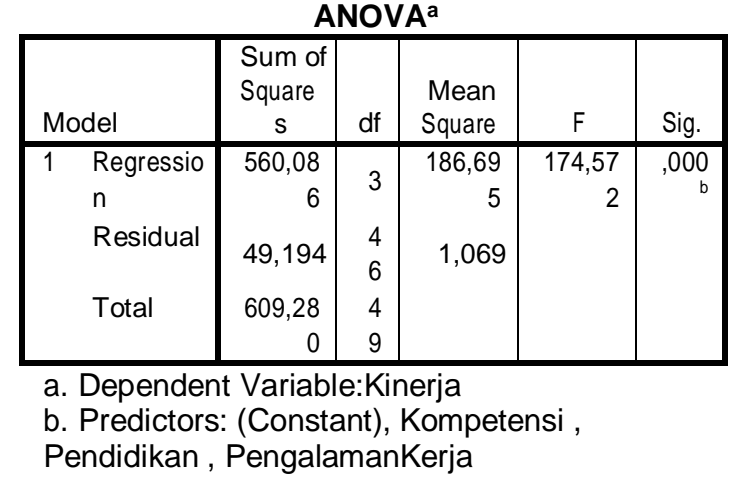

Hasil uji $F$ memperlihatkan nilai $F$ sebesar 174,572 ( $F$ hitung) > 3,183 (F tabel) dan nilai probabilitas signifikansi sebesar $0,000<0,05$ sehingga keputusan yang diambil adalah $\mathrm{H}_{\mathrm{o}}$ ditolak dan $\mathrm{H}_{\mathrm{a}}$ diterima. Hasil ini menunjukkan bahwa variabel Kompetensi (X1), Pelatihan (X2) dan Promosi jabatan (X3) mampu menjelaskan keragaman dari variabel terikat secara bersama-sama terhadap variabel kinerja pegawai(Y) dan bentuk regresi linear sudah tepat.

\section{Uji Koefisien Determinasi (R2)}

Model Summaryb 


\begin{tabular}{l|c|r|r|c|}
\hline Model & $\mathrm{R}$ & $\begin{array}{c}\mathrm{R} \\
\text { Square }\end{array}$ & $\begin{array}{c}\text { Adjusted } \\
\mathrm{R} \\
\text { Square }\end{array}$ & $\begin{array}{c}\text { Std. } \\
\text { Error of } \\
\text { the } \\
\text { Estimate }\end{array}$ \\
\hline 1 &, $959^{\mathrm{a}}$ &, 919 &, 914 & 1,03414 \\
\hline
\end{tabular}
a. Predictors: (Constant), Promosijabatan,
Pelatijan Kopetensi
b. Dependent Variable: Kinerjapegawai

Tabel memperlihatkan nilai $\mathrm{R}$ sebesar 0,959 artinya korelasi antara variabel Kompetensi (X1), Pelatihan (X2) dan Promosi Jabatan (X3), terhadap variabel kinerja pegawai $(\mathrm{Y})$ sebesar 0,959.Hal ini berarti bahwa hubungan variabel bebas terhadap variabel terikat melebihi 505 dan mendekati 1 sehingga terjadi hubungan yang erat. Hasil pengujian nilai Adjusted R Square sebesar 91,4\% dari kinerja karyawandapat dipengaruhi oleh variabel Kompetensi (X1), Pelatihan (X2) dan Promosi Jabatan (X3). Sisa 8,6\% kinerja dipengaruhi oleh variabel-variabel lain yang tidak dijelaskan dalam penelitianini.

\section{KESIMPULAN}

Berdasarkan hasil penelitian dan pembahasan yang telah dilakukan pada bab sebelumnya, maka dapat disimpulkanbahwa:

\section{Pengaruh Kompetensi Terhadap Kinerja Pegawai}

Berdasarkan hasil pengujian dapat dilihat bahwa kompetensi (X1) dengan nilai koefisien 0,293 berpengaruh secara positif terhadap kinerja pegawai. Nilai signifikan sebesar $0,003<0,05$ (nilai alpha) menunjukkan adanya hubungan yang signifikan antara kompetensi (X1) dengan kineraj perawat (Y). Hal ini diperkuat dengan hasil t hitung 3,194 > t tabel 2,009 menunjukkan bahwa variabel kompetensi (X1) berpengaruh secara positif dan signifikan terhadap kinerja pegawai.

\section{Pengaruh Pelatihan Terhadap Kinerja Pegawai \\ Berdasarkan hasil pengujian} dapat dilihat bahwa pelatihan(X2) dengan nilai koefisien 0,469 berpengaruh secara positif terhadap kinerja pegawai. Nilai signifikan sebesar $0,000<0,05$ (nilai alpha) menunjukkan adanya hubungan yang signifikan antara pelatihan(X2) dengan kinerja pegawai (Y). Hal ini diperkuat dengan hasil t hitung 4,020 > t tabel 2,009 menunjukkan bahwa variabel pegawai(X2) berpengaruh secara positif dan signifikan terhadap kinerja pegawai.

\section{Pengaruh Promosi Jabatan Terhadap Kinerja Pegawai}

Berdasarkan hasil pengujian dapat dilihat bahwa promosi jabatan(X3) dengan nilai koefisien 0,258 berpengaruh secara positif terhadap kinerja pegawai. Nilai signifikan sebesar 0,046 $<0,05$ (nilai alpha) menunjukkan adanya hubungan yang signifikan antara promosi jabatan(X3) dengan kinerja pegawai (Y). Hal ini diperkuat dengan hasil t hitung 2,051>t tabel 2,009 menunjukkan bahwa variabel promosi jabatan(X3) berpengaruh secara positif dan signifikan terhadap kinerja pegawai.

\section{Pengaruh Kompetensi, Pelatihan dan Promosi Jabatan Terhadap Kinerja Pegawai.}

Hasil uji F menunjukkan bahwa nilai signifikan dari 3 variabel bebas yaitu variabel Kompetensi (X1), Pelatihan (X2) dan Promosi Jabatan (X3) sebesar 0,000 dan $F$ hitung 174,572. Hasil ini memperlihatkan bahwa variabel Kompetensi (X1), Pelatihan (X2) dan Promosi Jabatan (X3), secara bersama-sama memiliki 
pengaruh yang signifikan terhadap kinerja Pegawai(Y).

Berdasarkan hasil penelitian diatas, terhadap hipotesis yang diajukan dalam penelitian ini dapat diberi kesimpulan sebagaiberikut:

H1. Terdapat pengaruh signifikan kompetensi terhadap kinerja pegawaidi Dinas Penanaman Modal dan Pelayanan Terpadu Satu Pintu Kota Batam, dinyatakan diterima. Hal ini dibuktikan dengan nilai signifikan sebesar $0,003<0,05$ (nilaialpha).

H2. Terdapat pengaruh signifikan pelatihan terhadap kinerja pegawai di Dinas Penanaman Modal dan Pelayanan Terpadu Satu Pintu Kota Batam,

\section{SARAN}

Berdasarkan hasil penelitian ini, beberapa saran/rekomendasi yang dapat diberikan kepada perusahaan maupun untuk penelitian yang akan datang sebagaiberikut:

1. Agar produktivitas kerja karyawan di Dinas penanaman modal dan pelayanan terpadu satu pintu kota batam tetap tinggi, maka perusahaan harus tetap memperhatikan para karyawannya, dengan cara mempertahankan atau meningkatkan Kompetensi sdm,pelatihan dan promosi jabatan. Karena

berdasarkan hasil penelitian ini ketiga variable tersebut sangat mempengaruhi Kinerja pegawai karyawan di Dinas penanaman modal dan pelayanan terpadu satu pintu kotabatam.

2. Untuk peneliti selanjutnya terkait produktivitas kerja dinyatakan diterima. Hal ini dibuktikan dengan nilai signifikan sebesar $0,000<0,05$ (nilaialpha).

H3. Terdapat pengaruh signifikan promosi jabatan terhadap kinerja pegawai di Dinas Penanaman Modal dan Pelayanan Terpadu Satu Pintu Kota Batam, dinyatakan diterima. Hal ini dibuktikan dengan nilai signifikan sebesar $0,046<$ 0,05 (nilaialpha).

H4. Terdapat pengaruh signifikan kompetensi, pelatihan dan promosi jabatan secara simultan atau bersama -sama terhadap kinerja pegawai di Dinas Penanaman Modal dan Pelayanan Terpadu Satu Pintu Kota Batam. Hal ini dibuktikan dengan nilai signifikan uji $\mathrm{F}$ sebesar 0,000 < 0,05 (nilai alpha).

karyawan di perusahaan perlu melihat faktor- faktor lain atau mengembangkan lebih banyak menggunakan variabel independen, misalnya pelatihan kerja, lingkungan kerja, kepemimpinan, motivasi dan kemampuan dan lain sebagainya, serta melibatkan lebih banyak responden dalam melakukan penelitian yang dapat mempengaruhi produktivitas kerja karyawan.

3. Hendaknya pihak Pimpinan memberikan pembinaan kepada karyawannya agar keterampilan dan pelatihan kerja Dinas penanaman modal dan pelayanan terpadu satu pintu kota batam.semakin meningkat, sehingga saat bekerja mereka akan merasa lebih mudah dalam mengerjakan pekerjaan dan juga tidak merasa pekerjaan yang mereka lakukan adalah suatubeban. 


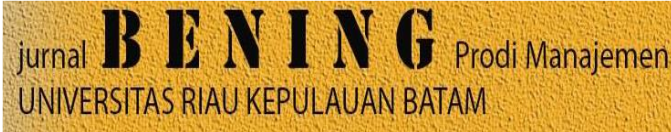

4. Peneliti selanjutnya dapat mengembangkan penelitian ini dengan menggunakan metode lain dalam meneliti Kompetensi SDM, Pelatihan dan promosi jabatan terhadapKinerja Pegawai,

\section{DAFTAR PUSTAKA}

Aldionita, Mella. (2014). Hubungan Konflik dengan Kinerja Pegawai Biro Bina Sosial Sekretariat Daerah Provinsi.SumateraBarat.

Armanu dan Mandayanti.(2012). Pengaruh

$$
\text { Pemberdaya }
$$

an Psikologis dan Komitmen Afektif Terhadap Kepuasan Kerja dan Kinerja Pegawai (Studi Pada Dinas Tata Kota dan Pengawasan Bangunan Kota Mataram). Mataram.

Crissida, Herry.(2013). Pengaruh Budaya

Organisa

si, Lingkungan Kerja Fisik, dan Disiplin Kerja terhadap Kenerja Karyawan Pada PT. Summit OTO Finance Cabang Jember.Skripsi.Jember.

Fahmi, Irham. (2011). Manajemen Teori Kasus dan Solusi.Bandung: Alfabeta.

Ghozali, Imam. (2005). Aplikasi Analisis Multivariate dengan Program

SPSS.Semarang:Badan Penerbit Universitas Diponegoro.

Kiswuryanto, Aditya. (2014).

Analisis Pengaruh Kompensasi dan

LingkunganKerja Terhadap

Kinerja Karyawan Dengan

Kepuasan Kerja
Volume 6 No. 2 Tahun 2019

P-ISSN 2252-5262

E-ISSN 2614-499

misalnya melalui wawancara mendalam terhadap responden, sehingga informasi yang diperoleh dapat lebih bervariasi daripada angket yang jawabannya telah tersedia.

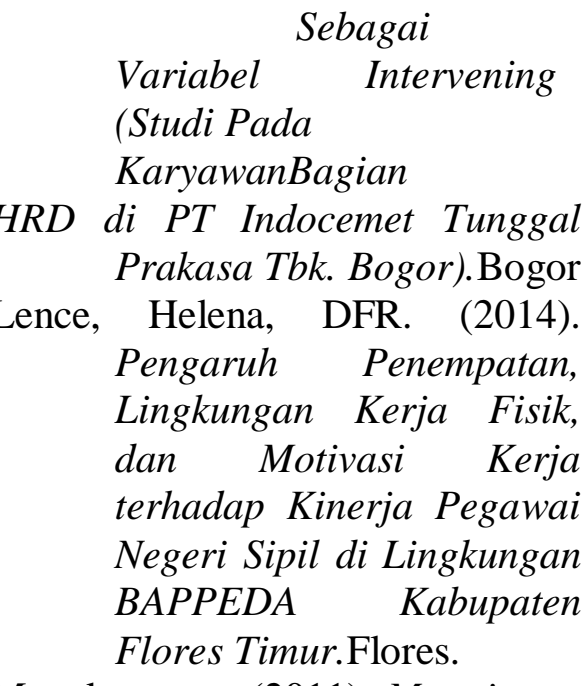

Mangkunegara.(2011). Manajemen Sumber Daya Manusia Perusahaan.Bandung: PT. Remaja Rosdakarya.

Maulana, Subechi, M. (2015).Pengaruh Konflik dan Lingkungan Kerja terhadap Kinerja Karyawan PDAM Tirta Moedal Kota Semarang.Skripsi.Semaran $\mathrm{g}$

Novianto, Risky, Aribowo. (2011). Pengaruh

Kepemimpi nan, Motivasi, dan Lingkungan Kerja Fisik terhada Kinerja Karyawan (Studi Pada CV. Karya Mitra Putra Rembang Devisi Kayu).Skripsi. Semarang.

Ratnasari, Sri Langgeng., Gandhi Sutjahjo., Adam. (2019). Employees' Performance: Organizational Culture And 
Leadership Style Through Job Satisfaction. Humanities \& Social Science Reviews. eISSN: 2395-6518, Vol.7, No.5, 2019, pp 597-608.

Ratnasari, Sri Langgeng., Gandhi Sutjahjo., Adam. (2019). The Contribution Of Competence, Motivation, And Creativity Towards Teacher's Performance Through Work Satisfaction. International Journal of Engineering and Advanced Technology (IJEAT). ISSN: 2249-8958, Volume-8 Issue 5C, May 2019, pp 145-149.

Sedarmayanti. (2014). Manajemen Sumber Daya Manusia, Reformasi Birokrasi dan

Wijono, Sutarto. (2010). Psikologi Industri dan Organisasi.Jakarta: MediaGrafika.

Wulandari, Sofi. (2013). Pengaruh Manajemen Konflik terhadap Kinerja Karyawan Pada PT. Taspen (PERSERO) Kantor Cabang

Yogyakarta.

Yogyakarta.

Yunus, Rahmat. (2014). Pengaruh Lingkungan Kerja dan Stres Kerja Terhadap Kinerja Karyawan pada PT. Hadji Kalla Cabang Alauddin Makasar.Skripsi.Makassar.Univ ersitas

Hasanuddin. (http://repository.unhas.ac.id/ha ndle).
Manajemen

Pegawai

Negeri Sipil.Bandung: Refika Aditama.

Setiawan, Ivonne., Sri Langgeng Ratnasari, Lukmanul Hakim. (2019). The Effects of Organizational Culture, Leadership Motivation, Style, Organizational Commitment on Employee Work Discipline at Pancaran Maitri Foundation. Management Research Spectrum. Vol. 9. No. 1. (2019) 42-47.

Sugiyono.(2014).

Metode Penelitian Kombinasi (Mixed Methods).Bandung: Alfabeta. 